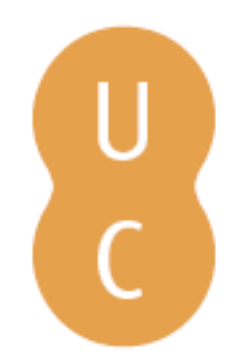

\title{
pommalina
}

\section{Aplicação do conceito de eco-bairro num bairro do município da Amadora: uma abordagem experimental}

\author{
Autor(es): $\quad$ Pereira, Susana \\ Publicado por: Imprensa da Universidade de Coimbra \\ URL \\ persistente: URI:http://hdl.handle.net/10316.2/30851 \\ DOI: $\quad$ DOI:http://dx.doi.org/10.14195/978-989-26-0244-8_57 \\ Accessed : $\quad$ 26-Apr-2023 13:07:06
}

A navegação consulta e descarregamento dos títulos inseridos nas Bibliotecas Digitais UC Digitalis, UC Pombalina e UC Impactum, pressupõem a aceitação plena e sem reservas dos Termos e Condições de Uso destas Bibliotecas Digitais, disponíveis em https://digitalis.uc.pt/pt-pt/termos.

Conforme exposto nos referidos Termos e Condições de Uso, o descarregamento de títulos de acesso restrito requer uma licença válida de autorização devendo o utilizador aceder ao(s) documento(s) a partir de um endereço de IP da instituição detentora da supramencionada licença.

Ao utilizador é apenas permitido o descarregamento para uso pessoal, pelo que o emprego do(s) título(s) descarregado(s) para outro fim, designadamente comercial, carece de autorização do respetivo autor ou editor da obra.

Na medida em que todas as obras da UC Digitalis se encontram protegidas pelo Código do Direito de Autor e Direitos Conexos e demais legislação aplicável, toda a cópia, parcial ou total, deste documento, nos casos em que é legalmente admitida, deverá conter ou fazer-se acompanhar por este aviso.

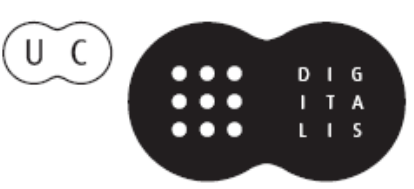




\section{TRUNFOS DE UMA}

\section{EOGRAFIA ACIVA}

\section{DESENVOLVIMENTO LOCAL,}

AMBIENTE,

ORDENAMENTO

E TECNOLOGIA

Norberto Santos

Lúcio Cunha

COORDENAÇÃO 
Susana Pereira

Câmara Municipal da Amadora, Gabinete SIG

\section{APLICAÇĀO DO CONCEITO DE ECO-BAIRRO NUM BAIRRO DO MUNICÍPIO DA AMADORA: UMA ABORDAGEM EXPERIMENTAL}

\section{INTRODUÇÃO}

O Programa Operacional Regional de Lisboa assenta nas grandes recomendaçóes da Política de Coesão, no desígnio estratégico do Quadro de Referência Estratégico Nacional e ancora-se na Estratégia Regional, Lisboa 2020.

O Município da Amadora apresentou, em Agosto de 2009, candidatura ao Projecto "Programas integrados de criação de Eco-Bairros", contemplado nos Objectivos específicos do Eixo Prioritário ii. sustentabilidade territorial, no âmbito das Parcerias para a Regeneração Urbana, que por sua vez se contextualizam nos instrumentos de política ${ }^{1}$ previstos na Política de Cidades Polis XXI.

Em complemento, a "Estratégia Regional, Lisboa 2020" preconiza um modelo urbano revalorizado capaz de assumir o paradigma do desenvolvimento sustentável. Para tal, prevê a realização de 2 ou 3 experiências em bairros ou Freguesias, que se distingam pela promoção de práticas sustentáveis aplicadas ao espaço urbano, para posterior replicação, nos termos do previsto no Projecto 4.2-Eco-bairro.

Segundo o Aviso no5-PRU do PORL entende-se por eco-bairro: as áreas que com base nos princípios do desenvolvimento sustentável adoptem de forma integrada e articulada equipamentos, redes de infra-estruturas, técnicas, metodologias e boas práticas que permitem rentabilizar a gestão e utilização dos diversos recursos necessários ao quotidiano e vivência da população, nomeadamente energia, água, resíduos, transportes mobilidade e espaço público, melhorando desta forma o desempenho ambiental do bairro no seu todo (espaço interior e exterior), promovendo a sustentabilidade ambiental, social, económica e cultural da área de intervenção, com impactes positivos para a qualidade de vida e quotidiano da populaçáo.

Do Regulamento da candidatura destacam-se critérios determinantes na delimitação da área de intervenção e na redacção do Programa de Acção, tais como:

- tipologia das áreas: áreas urbanas consolidadas ou novas áreas em contínuo urbano que formem um todo sócio-económico e cultural coerente e que contenham usos mistos; a área deve dimensionar-se entre os 15 ha e os 200ha e com uma população entre os 3.000 e os 20.000 habitantes;

\footnotetext{
${ }^{1}$ Instrumentos de política do Polis XXI: parcerias para a regeneração urbana; redes urbanas para a competitividade e inovação; acçôes inovadoras para o desenvolvimento urbano; equipamentos estruturantes do sistema urbano nacional.
} 
- tipologia de acçóes: resíduos sólidos urbanos; utilizaçáo sustentável da água nos espaços públicos, iluminação do espaço público de alta eficiência energética; mobilidade e acessibilidade;

- tipologia dos parceiros: parceiros locais, regionais, centrais; entidades fornecedoras e gestoras de serviços (água, energia); parceiros económicos, sociais, educativos, culturais, etc.

O Regulamento definia ainda as metas a alcançar no termo dos dois anos após a conclusão do PA, incidindo sobre domínios como: redução do consumo de água potável e de energia utilizada nos espaços públicos, produção de energia com recurso a fontes alternativas, recolha selectiva de RSU, etc.

Os limites de investimento elegível situavam-se entre os 2,5 e os 10 milhôes de euros, sendo o limite máximo de incentivo a atribuir de $35 \%$.

\section{CARACTERIZAÇÃO DA ÁREA DE INTERVENÇÃO DA CANDIDATURA}

A área delimitada na candidatura reúne um conjunto de características específicas que se enquadram nos critérios enunciados no Regulamento e nas Orientaçóes Técnicas, sob pena da não aceitação da candidatura, mas também congrega alguns dos princípios subjacentes ao modelo da cidade compacta, que devem ser potenciados (proximidade, mistura de usos e mobilidade).

Com cerca de 33 ha e 5900 residentes $^{2}$, a AI localiza-se a norte da estação de caminho de ferro da Amadora, e insere-se no continuum urbano Portas de Benfica-Venda Nova Falagueira, induzida pela expansão industrial e habitacional sustentada pela Rua Elias Garcia (via que atravessa o Município no sentido Oeste-Este e que permite a penetração a Lisboa). Abarca parte da designada Zona Centro da Cidade, que está na génese da formação do Município, constituiu uma área comercial quantitativa e qualitativa superior e goza da proximidade a um dos maiores interfaces multimodais da AML-N. Contudo, a AI, nunca deteve a capacidade polarizadora verificada no território a sul (mais dinâmica mas também sujeita a pressóes de renovação urbana), factor determinante para a manutenção da imagem de unidade e identidade.

A AI apresenta-se com um espaço urbano consolidado onde predomina o tecido de quarteiróes, onde a rua tem uma grande significado formal e funcional e uma malha mais complexa, estruturada pelos acessos aos núcleos rurais pré-existentes, muito condicionado pela propriedade rústica.

Desde o início do século XX sofreu com os surtos de crescimento demográfico ocorridos no Município, ainda assim suportadas por estudos de planeamento ${ }^{3}$ que, embora ancorados em pressupostos ligeiramente diferentes preconizavam a criação de áreas habitacionais de qualidade. Como resultado, é possível encontrar diferentes tipologias que vão desde as moradias inspiradas na "cidade-jardim", aos edifícios de 3 ou 4 pisos com jardim fronteiro, constituindo a maioria dos edifícios abrangidos, às elevadas densidades das décadas de 70 , até às operaçóes pontuais de renovação urbana realizadas nos últimos anos (mais cuidadas e

\footnotetext{
${ }^{2}$ Fonte: INE, Censo2001.

${ }^{3}$ Projecto do Grande Bairro Parque da Mina do início do Século XX, inaugurado pelo Presidente da República, Manuel de Arriaga, em 1913, o Plano de Urbanização da Amadora de 1949, o Plano de Urbanização da Freguesia da Amadora de 1960, Projecto Centro da Amadora, 1984.
} 
exigentes em virtude da regulamentação introduzida pelo PDM). Não obstante a diversidade, a AI encerra uma forte imagem de unidade e referência urbana e reúne um repositório de elementos patrimoniais classificados (nacionais e de interesse municipal) e de outros que se encontram em processo de classificação.

O território da AI possui eixos que sustentam uma parte significativa da distribuição do tráfego dos movimentos pendulares gerados no Município e nos Municípios contíguos, por permitir a entrada na Capital e constituiu um ponto para onde convergem os movimentos intraconcelhios, em transporte público e particular por permitir a transposiçáo da barreira física representada pela linha de caminho de ferro (viaduto do Alto Maduro).

$\mathrm{O}$ facto de se estar perante um tecido urbano consolidado, com fortes limitaçôes à circulação face à dimensão das vias urbanas, que por sua vez condicionam a penetração das carreiras de transporte público rodoviário (cujo trajecto alternativo se processa em torno do bairro) associada às condiçóes topográficas do território, são os factores determinantes para que a acessibilidade pedonal na AI saia reforçada. Não obstante, a acessibilidade pedonal aos pontos de oferta de transporte rodoviário é bastante favorável, uma vez que a populaçáo da AI está na sua maioria dentro da primeira coroa da área de influência de uma ou mais paragens, o que se traduz em deslocaçóes a pé inferiores a 3 minutos.

Esta área congrega os principais serviços públicos de natureza administrativa (Paços do Concelho, Junta de Freguesia, posto da PSP, Serviços Municipalizados de Água e Saneamento), equipamentos de educação e ensino de natureza pública e privada que cobrem vários níveis de ensino (destaca-se a presença um pólo de do ensino superior público)4, acção social, cultural, actividades financeiras, serviços ligados à prestação de cuidados de saúde (consultórios, meios de diagnóstico), farmácias, mercado municipal, comércio a retalho e serviços pessoais, etc. A AI beneficia ainda da proximidade a duas zonas verdes de lazer e estadia de nível supramunicipal: o Parque Central da Amadora e o Parque Aventura, que comporta um importante elemento patrimonial da AI, a Casa de Ordem de Malta, onde funciona o Núcleo Museográfico da Falagueira.

No que diz respeito à cobertura por meios de deposição de RSU, o investimento do Município neste domínio é visível em todo o território municipal e em particular na AI, quer para os resíduos indiferenciados quer para os valorizáveis.

\section{PERTINÊNCIA DA CANDIDATURA}

Conforme foi explanado, a AI congrega alguns dos argumentos favoráveis ao modelo inspirado na cidade compacta. Acresce o facto de que no território do Município e em particular na AI estar a decorrer uma sucessáo de investimentos de iniciativa municipal, que colocam a Amadora numa posição pioneira no domínio da requalificação do espaço urbano e da valorização ambiental, a saber:

- Metro Ligeiro de Superfície, transporte inovador de média capacidade, amigo do ambiente, desenvolve a $1^{\text {a }}$ fase do traçado proposto num troço junto AI, foi alvo de cândidatura ao QREN, também no Eixo ii do POR - Mobilidade territorial.

- Áreas de Reabilitaçáo Urbana, criadas no âmbito do Regime Extraordinário de Reabilitação Urbana previsto na Lei de Orçamento de Estado de 2008 e 2009; regula a con-

\footnotetext{
${ }^{4}$ Instituto Politécnico de Lisboa-Escola Superior de Teatro e Cinema
} 
cessão de incentivos fiscais às acções de reabilitação de imóveis (Art ${ }^{\circ} 79^{\circ}$ da LOE). Na AI foram delimitadas e aprovadas duas ARU.

- Requalificação do Parque Central, união de dois parques criando assim um único parque de grande dimensão, inserido na malha urbana. Esta obra permitiu transformar uma via urbana de grande movimento em TP e TI num percurso pedonal que passará a integrar o parque, destinada a acolher actividades diversas e envolvido por um corredor verde de grande riqueza ornamental; o reordenamento do trânsito permitiu ainda a criação de 140 lugares de estacionamento beneficiando residentes e comerciantes. O Parque ainda comporta um edifício multi-usos de onde se destaca a instalação de um Centro de saúde e bem estar, o Centro de Educação Ambiental, substituindo o actual Eco-espaço.

- No domínio dos RSU são muitas as iniciativas: recolha selectiva de óleos alimentares usados, em colaboração com a Fundação de Assistência Médica Internacional/Pingo Doce Distribuição Alimentar para recolher selectiva de óleos alimentares usados, promove a recolha selectiva de resíduos orgânicos e tem por objectivo a produção de composto para a agricultura e, ainda, a produção de energia eléctrica, na Estação de Tratamento e Valorização Orgânica da Valorsul (ETVO), localizada na freguesia de São Brás, sendo beneficiários as escolas do concelho, cantinas municipais, mercados municipais, supermercados, frutarias e estabelecimentos de restauração; o PROCICLA, destinado aos estabelecimentos comerciais do município produtores de papel e de cartão.

- ECO XXI, destinado aos Municípios, visa distinguir as boas práticas no sentido da sustentabilidade; inspirado nos objectivos da Agenda 21, procura, através de um sistema de 23 indicadores, avaliar diversas vertentes da sustentabilidade e da qualidade ambiental. A Amadora apresentou a sua $1^{\text {a }}$ candidatura em 2007 e depois em 2008, tendo obtido nos 2 anos o galardáo máximo (bandeira).

- Agenda 21 Local da Amadora, em elaboração.

- o Eco-Espaço é um serviço municipal de promoção de educação ambiental dirigido em particular aos alunos do $1^{\circ}$ ciclo ao ensino secundário, incluindo o técnico-profissional; todos os anos lectivos apresenta publicamente o seu Programa, que desenvolve desde Novembro até Junho.

- a Câmara Municipal e a EDP estão a estudar a implementação no Concelho do projecto-piloto INOVGRID, uma iniciativa liderada pela EDP que reuniu parceiros tecnológicos e de sistemas (EFACEC, JANZ/CONTAR e LOGICA) e o INESC-Porto; pretende observar-se no terreno quais as vantagens e desvantagens, técnicas, comerciais, etc para a rede suportar novos serviços aos clientes e promover neles mudanças comportamentais no sentido de uma maior atenção aos aspectos de poupança de energia e de preservação do ambiente. $\mathrm{O}$ projecto tem uma primeira fase já concluída com construção de protótipos e testes, a qual é parcialmente participada pelo QREN; pretende realizar-se um projecto-piloto e a AI pode vir a integrar a lista das áreas seleccionadas, caso cumpra os requisitos técnicos exigidos.

Neste contexto, a candidatura visa em primeiro lugar cumprir os objectivos definidos no ${ }^{\circ} 2$ do Aviso de abertura do Regulamento, as metas estabelecidas após dois anos de implementação do PA, procurar que todo o espaço público se nivele pela bitola que as intervençóes recentes definiram do que se pretende para a Cidade e promover uma reabilitação urbana sustentável que extravase o espaço público e se expanda também ao edificado de natureza particular. Com efeito, na AI tem-se vindo a verificar o fenómeno de requalificação do espaço público, ao passo que o espaço privado se mantém intocado. 


\section{Plano de ACÇÃo}

O PA a candidatar ir-se-á concretizar em 5 Domínios de Desenvolvimento, a saber: Qualificação do espaço público e do ambiente urbano; Desenvolvimento Económico; Desenvolvimento social; Desenvolvimento cultural; Animação da Parceria Local. Naturalmente relacionados entre si, estes domínios serão detalhados em projectos e acçóes, podendo revestir uma natureza âncora ou de enriquecimento (Anexo I). Em primeiro lugar destaca-se a tipologia dos projectos admitidos no Regulamento e que concretizam o PA, repartidos por cada um dos Domínios de Desenvolvimento.

Para o DD 1 foram considerados: a) melhoria do ambiente urbano, criação e qualificação de espaços verdes públicos; b) melhoria da acessibilidade e mobilidade, promovendo os modos de transporte favoráveis ao ambiente, a circulação ciclável, a criaçáo de percursos acessíveis, a reestruturação da rede viária e a criação de estacionamento adequado; c) apoio técnico aos moradores e aos agentes económicos para a reabilitação e reconversão de edifícios para a sua adaptaçáo à eco-eficiência energética e à reciclagem e reutilização de resíduos; d) modernização de infra-estruturas urbanas que permitam a utilização mais sustentável dos recursos; e) reforço da sustentabilidade através da promoção da eficiência ambiental de edifícios; f) reabilitação de equipamentos colectivos de identidade e referência urbana com soluçóes técnicas e urbanísticas que promovam uma maior eficiência energética e uma utilização mais racional da água; g) recuperação e qualificação do espaço público, que promova a sua sustentabilidade ambiental e a eficiência ambiental.

Para o DD 2 foram definidos: a) desenvolvimento de novas oportunidades de qualificação, de auto-emprego e de empreendedorismo, em que se privilegia a exploraçáo do potencial das TIC e de novas tecnologias amigas do ambiente; b) animação económica e fomento do empreendedorismo;

No DD 3 foram considerados: a) dinamização de actividades de sensibilização e promoção de comportamentos ambientais, privilegiando a cooperação com estabelecimento de ensino; b) dinamização de actividades de sensibilizaçáo e promoção de comportamentos ambientais; c) qualificação e modernização dos serviços de interesse colectivo para a população; d) promoçáo de melhores condiçóes de vida para cidadãos com dificuldades especiais.

Para o DD 4 foram formuladas acçóes de dinamização de actividades culturais em espaços públicos e de lazer.

Por fim, para o DD 5 prevê-se a dinamização do Programa de Acção.

A Política de Cidades PolisXXI vem reforçar a necessidade das parcerias de base local, demonstrado que o sucesso das acçóes e a sustentabilidade futura dos projectos ligados ao território depende em larga escala do número de parceiros, do seu contributo e cooperação/ lenvolvimento.

O Município identificou um conjunto de parceiros. Desses, responderam favoravelmente ao convite os seguintes: SMAS Oeiras e Amadora, Agrupamento de Escolas Cardoso Lopes, Escola Profissional Gustave Eiffel, Espaço e Desenvolvimento (consultores), Juntas de Freguesia da AI, Grupo EDIFER Ambiente e Associação Comercial e Empresarial dos Concelhos de Oeiras e Amadora. Foi naturalmente identificado o contributo de cada parceiros para a concretização do PA dadas as valências cumulativas de que cada um deles goza.

O Modelo de Gestáo do Programa de Acção compreende duas estruturas: a Unidade de Direcção liderada pelo Município, que será assessorada por uma Estrutura de Apoio Técnico 
e um Conselho Alargado de Parceiros; o Conselho Alargado de Parceiros, constituído por todos os Parceiros Locais, poderá ser segmentado em grupos de trabalho temáticos.

Tabela - Resumo do Plano de Acção

\begin{tabular}{|c|c|c|c|c|c|}
\hline \multirow{8}{*}{ 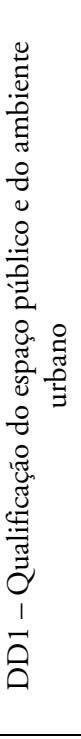 } & $\mathrm{P}^{*}$ & $A^{* *}$ & Descrição das acçōes & $\begin{array}{l}\text { Ân- } \\
\text { cora }\end{array}$ & Enriq \\
\hline & a) & 4 & $\begin{array}{l}\text { Requalificaçáo paisagística: taludes, pracetas, espaços } \\
\text { urbanos residuais e parque urbano }\end{array}$ & 1 & 3 \\
\hline & b) & 3 & $\begin{array}{l}\text { Avaliaçáo das necessidades de estacionamento local, criaçáo } \\
\text { de estacionamento subterrâneo, promoçáo de rede ciclável }\end{array}$ & 2 & 1 \\
\hline & c) & 3 & $\begin{array}{l}\text { Intervençóes planeadas nas fachadas das edificaçóes envol- } \\
\text { ventes aos espaços públicos recentemente qualificados (área- } \\
\text {-piloto), elaboraçâao de manual de boas práticas da construçáo } \\
\text { sustentável para edifícios existentes e em fase de projecto, } \\
\text { monitorizaçáo de consumos energéticos na área-piloto }\end{array}$ & 2 & 1 \\
\hline & d) & 6 & $\begin{array}{l}\text { Recolha, armazenamento e tratamento de águas residuais } \\
\text { domésticas, aproveitamento de águas subterrâneas, adopçáo de } \\
\text { soluçóes alternativas para a produção de iluminaçáo pública }\end{array}$ & 4 & 2 \\
\hline & e) & 2 & $\begin{array}{l}\text { Soluçóes fotovoltaicas e térmicas para produção de energia } \\
\text { em edifícios públicos }\end{array}$ & & 2 \\
\hline & f) & 2 & Reabilitaçâo de edifícios públicos & 1 & 1 \\
\hline & g) & 2 & $\begin{array}{l}\text { Instalação de jardins verticais como bandas acústicas, criaçáo } \\
\text { de mecanismos de aproveitamento de águas pluviais, } \\
\text { aplicando pavimentos drenantes }\end{array}$ & 2 & \\
\hline \multirow{2}{*}{ 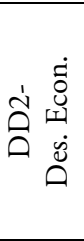 } & a) & 1 & $\begin{array}{l}\text { Criaçáo de um centro de empreendedorismo a ligar à rede } \\
\text { TheHub em todo o mundo }\end{array}$ & 1 & \\
\hline & b) & 3 & $\begin{array}{l}\text { Criaçáo de imagem distintiva que constitua uma certificação } \\
\text { para o comércio local; planos de mobilidade empresarial } \\
\text { para os maiores empregadores da AI; feiras destinadas a } \\
\text { promover a reutilizaçáo de materiais }\end{array}$ & & 3 \\
\hline \multirow{4}{*}{ 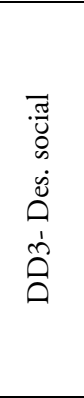 } & a) & 2 & $\begin{array}{l}\text { Promoçáo e sensibilização ambiental dirigida aos alunos } \\
\text { sobre alteraçôes climáticas, consumo sustentável etc }\end{array}$ & 2 & \\
\hline & b) & 3 & $\begin{array}{l}\text { Sensibilização/acompanhamento para a redução dos gastos } \\
\text { energéticos domésticos, campanhas de trocas de } \\
\text { electrodomésticos, recolha de dejectos animais }\end{array}$ & 2 & 1 \\
\hline & c) & 1 & $\begin{array}{l}\text { Instalação de dispositivos de poupança de água na rede in- } \\
\text { terna dos consumidores }\end{array}$ & 1 & \\
\hline & d) & 3 & $\begin{array}{l}\text { Recolha de materiais destinados à reutilização para fins } \\
\text { sociais, circuitos destinados à população sénior; } \\
\text { empreendedorismo social }\end{array}$ & 1 & 2 \\
\hline 焉 & a) & 2 & $\begin{array}{l}\text { Concursos destinados à promoçáo de ideias eco-eficientes; } \\
\text { acçóes entre moradores e artistas convidados destinadas a } \\
\text { projectar a requalificação de logradouros que requerem a } \\
\text { melhoria da imagem e da sustentabilidade daqueles espaços }\end{array}$ & 1 & 1 \\
\hline 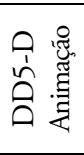 & a) & 3 & $\begin{array}{l}\text { Criação de portal de divulgação; realização de campanhas } \\
\text { de promoção e sensibilização geral e especifica; avaliação da } \\
\text { implementaçáo dos projectos e divulgação de resultados; } \\
\text { articulação com o site da Agenda } 21 \text { Local da Amadora }\end{array}$ & 1 & 2 \\
\hline
\end{tabular}

* Projecto; ** Acçôes 


\section{CONCLUSÓES}

Em síntese, pese embora a expectativa na aprovação da candidatura, o Município reconhece que passará a dispor de um instrumento que enquadra e sistematiza um conjunto de intervençôes já agendadas, outras pioneiras mas dispersas e associa outras nos domínios da requalificação, física e funcional, e gestão eficiente dos recursos, concretizando assim as recomendaçóes descritas no Relatório de Estado de Ordenamento do Território da Amadora $^{5}$, para uma determinada parcela do território municipal.

\section{REFERÊNCIAS BIBLIOGRÁFICAS}

Presidência do Conselho de Ministros, 2006 Estratégia Nacional de Desenvolvimento Sustentável 2015 Disponível http://www.apambiente.pt/politicasambiente/DesenvolvimentoSustentavel

Amado, M. P. 2009 Planeamento Urbano Sustentável, Colecção Pensar Arquitectura, Caleidoscópio, 2a Ed, Casal de Cambra.

Batty, M., Bessussi, E. \& Chin, N. 2003 Urban Planning for Mobility. Urban Growth, Sprawl and the Compact City, Disponível em http://www.casa.ucl.ac.uk/

Comissão de Coordenação Regional de Lisboa e Vale do Tejo, 2009 Estratégia Regional Lisboa 2020, Disponível em http://www.gestaoestrategica.ccdr-lvt.pt/

Comissão de Coordenação Regional de Lisboa e Vale do Tejo, Programa Operacional de Lisboa 2007-2013 http://www.porlisboa.qren.pt/

Departamento de Prospectiva e Planeamento e Relações Internacionais, 2008 Politica de Cidades Polis XXI, Redes Urbanas para a competitividade e a inovação, Razôes para cooperar ideias a explorar, disponível em www.dpp.pt/ /pages/files/Redes_Urbanas_Relat_Final.pdf

Departamento de Prospectiva e Planeamento e Relaçôes Internacionais, 2007 Cidades inovadoras e competi-tivas para o desenvolvimento sustentável, Disponível em http://www.dpp.pt/pages/files/Relatorio_Cidades_ Inteligentes.pdf

Félix Ribeiro, J. \& Ponte da Silva, G. 2009, «Que formas urbanas para as cidades sustentáveis do futuro?» Ciclo de Workshops As formas e o Funcionamento das Cidades e os Desafios da Sustentabilidade, DPP/ANEOP, Lisboa

Ministério do Ambiente, do Ordenamento do Território e do Desenvolvimento Regional, 2007 Quadro de Referência Estratégico Nacional Portugal 2007-2013, Disponível em http://www.qren.pt/

Ponte da Silva, G. 2009, Forma Urbana e Sustentabilidade: algumas notas sobre o Modelo de Cidade Compacta Disponível em http://www.dpp.pt/ pages/files/Forma_Urbana.pdf

Rueda, S. La ciudad compacta y diversa frente a la conurbación difusa. Disponível em http://habitat.aq.upm.es/ /cs/p2/a009.html

Song, Y. \& Knaap G.2004 «Measuring Urban Form» Journal of American Planning Association, Vol. 70 No2

Uniāo Europeia 1990, Livro Verde do Ambiente Urbano, European Commission.

Uniāo Europeia, 2007 O Renascimento das Cidades, Carta de Leipzig Disponível em http://oge.risco.pt/ftp/ /RenascimentoDasCidades.pdf.

\footnotetext{
${ }^{5}$ Aprovado em Sessão de Câmara a 02.04.2008 e Assembleia Municipal a 29.04.2008
} 